\title{
DISCURSOS HETERONORMATIVOS E PRODUÇÃO DE SUJEITOS GENERIFICADOS NO CURRÍCULO ESCOLAR
}

\author{
Danilo Araújo de OLIVEIRA ${ }^{\mathbf{1}}$ \\ Universidade Federal de Sergipe-UFS \\ danilodinamarques@hotmail.com
}

Resumo: Este artigo é um recorte de uma pesquisa de mestrado e tem por finalidade analisar o funcionamento $d a$ heteronormatividade no currículo de uma escola de educação básica. A abordagem metodológica foi qualitativa, a partir de um posicionamento pós-crítico. Realizamos entrevistas abertas com sete docentes (cinco mulheres e dois homens) e a análise dos dados considerando discurso como categoria teórica. Os resultados da pesquisa informam que discursos normalizadores funcionam como demandas educativas, conferindo inteligibilidade de gênero aos corpos, marcando e regulando também aqueles/as que apresentam performance as quais se distanciam e rompem com as normas de gênero. Também foi observado que noções essencialistas sobre gênero $e$ sexualidade são acionadas, aprendidas $e$ ensinadas, mediante o atravessamento de discursos biológico e religioso nas narrativas, definindo e fixando duas identidades de gênero possíveis e opostas: masculina-homem/feminina-mulher. Os discursos que atravessam as narrativas reforçam a (re)produção da heterossexualização compulsória no currículo investigado, com poucas experiências de subversões.

Palavras-chave: Currículo Escolar. Heteronormatividade. Normas de Gênero.

\begin{abstract}
This article is a part from a master's research and aims to analyze the functioning of heteronormativity in the curriculum of a basic education school. The methodological approach was qualitative, based on a post-critical positioning. We conducted open interviews with seven teachers (five women and two men) and analyzed the data considering discourse as a theoretical category. The results of the research report that normalizing discourses function as educational demands, giving gender intelligibility to bodies, marking and regulating also those who perform, who distance themselves and break with gender norms. It was also observed that essentialist notions about gender and sexuality are triggered, learned and taught through the crossing of biological and religious discourses in the narratives, defining and fixing two possible and opposing gender identities: male-male / female-female. The discourses that go through the narratives reinforce the (re) production of compulsory heterosexualization in the curriculum investigated, with few experiences of subversions.
\end{abstract}

Keywords: $\quad$ School curriculum. Heteronormativity. Gender norms.

\footnotetext{
1 Mestre em Educação pela Universidade Federal de Sergipe (2017). Possui graduação em LETRAS PORTUGUÊS/INGLÊS pela Faculdade Atlântico (2013). Estudante no grupo de pesquisa EDUCAÇÃO, FORMAÇÃO, PROCESSO DE TRABALHO E RELAÇÕES DE GÊNERO, da Universidade Federal de Sergipe. Atuando principalmente nos seguintes temas: Corpo, Gênero e Sexualidades.
} 


\section{Introdução}

A partir de silenciamentos, práticas minuciosas, vigilância e controle, normas de gênero vão sendo interiorizadas e a sexualidade heterossexual vai sendo aprendida na escola como forma autorizada de existir; contudo, os detalhes e cuidado para a perpetuação denunciam os investimentos de uma naturalidade, além disso, os corpos que escapam, discordam e confrontam o padrão atrapalham seu projeto e narram outras possibilidades.

Ao ser ensinada na escola como modelo saudável, verdadeiro e normal, a heteronormatividade desencadeia processos diversos de homofobia, preconceito e outras violências que marginalizam e excluem sujeitos que não incorporam seus discursos. Problematizar as ações que reafirmem o regime de controle como parâmetro possibilita desestabilizar as certezas adquiridas nesse espaço, seu viés construtivo e logo não natural, assim "[...] mencionar sujeitos e violações a que estão sendo submetidos poderia implicar processos de reconhecimento não de suas existências sociais, mas de condições de sujeitos de direito" (JUNQUEIRA, 2015, p. 235). A escola é um importante espaço de subjetivação, por isso importa que seu currículo não priorize um modelo coercitivo, compulsório e sim seja um lugar para visibilizar os processos de normalização e as relações de poder que estão aí implicados “[...] por meio das pedagogias culturais e escolares, que controlam o sexo dos sujeitos e que, para isso, precisam ser constantemente repetidas e reiteradas para dar o efeito de substância, de natural e inquestionável" (CAETANO, 2011, p. 172).

Convém destacar que heterossexualidade compulsória é um regime político que interpela os sujeitos a partir de uma diversidade de artefatos culturais para que todas as pessoas sejam heterossexuais. Já heteronormatividade, ainda que permita outras possibilidades de desejo e relacionamento busca conformar os corpos para que se aproximem do modelo imposto pela heterossexualidade compulsória, ou seja, corpos marcados pelo pênis sejam masculinizados, machos e corpos com vagina tenham características comumente construídas como femininas, sejam delicadas. Esses modelos se convergem para produzir sujeitos normalizados e generificados e encontram espaço de (re)produção no currículo escolar.

Nesse sentido, o presente trabalho, recorte de uma pesquisa de mestrado, pretende problematizar como a heteronormatividade age no currículo de uma escola de educação básica para produzir sujeitos generificados. A escola oferece turmas do $6^{\circ}$ ano do Ensino 
Fundamental ao $3^{\circ}$ ano do Ensino Médio nos turnos matutino e vespertino e pertence a Rede Estadual de Sergipe. Aplicou-se uma abordagem qualitativa, pois ela é que mais se aproxima dos estudos culturais (HALL, 2003; MATTELART, 2004), pois as análises das normas de gênero e heteronormatividade são vertentes analíticas que mostram a construção de identidades masculinas e femininas no contexto social contemporâneo marcados/as pela diferença percebendo, dessa forma, as instâncias discursivas que caracterizam as pesquisas com essas temáticas, a partir das múltiplas visões que se complementam e produzem novas sínteses formando novas bases de pesquisa, das práticas e de políticas futuras (OLESEN, 2006).

Entende-se que as análises culturais estão comprometidas em evidenciar que o “[...] mundo cultural e social torna-se, na interação social, naturalizado: sua origem social é esquecida. A tarefa da análise cultural consiste em desconstruir, em expor esse processo de naturalização" (SILVA, 1999, p. 134).

Sob a influência de um posicionamento pós-crítico (HALL, 1997; PARAÍSO, 2012; SILVA, 1999), consideram-se as contribuições que essa vertente tem dado para questionar as práticas escolares, propondo a dúvida e novas formas de pensar os espaços formais pedagógicos, interrogando os currículos, problematizando o cotidiano e as formas de fazer educação num período em que mudanças significativas no tempo interferem na forma de se perceber e perceber o outro em um movimento de constante processo de construção e reconstrução de identidades que atestam a existência das diferenças que fazem a sala de aula e seus contornos.

Foram utilizadas entrevistas abertas, partindo do pressuposto de que as entrevistas não “[...] permitem dizer uma ou a verdade sobre as coisas e os fatos, mas pode-se considerá-las como a instância central que, somada a outras, traz informações fundamentais acerca do vivido e possibilita uma interpretação (mesmo que provisória e parcial)" (ANDRADE, 2012, p. 175). Assim, foi proposto que os/as docentes falassem o máximo de suas experiências de vida, de formação, de trabalho, valorizando a subjetividade no trabalho docente, e como essas experiências influenciam a forma desses/as professores/as conduzirem sua rotina. Foi necessário analisar o dito ou não dito nas entrevistas, pois esse procedimento possibilita a compreensão dos discursos (contradições, incoerências, omissões, lacunas, silêncios).

Por isso, nesta pesquisa, foi considerado discurso como categoria teórica, pois a heteronormatividade é um processo de subjetivação que busca interpelar os sujeitos para 
que se conformem ao seu discurso, entende-se que "[...] mais do que subjetivo, o discurso subjetiva [...]" (VEIGA-NETO, 2007, p. 99), dessa forma importa perceber quais discursos estão circulando na escola para produzir sujeitos específicos, assim busca-se mostrar que diferentes discursos atravessam o currículo investigado "[...] remetem uns aos outros, se organizam em uma figura única, entram em convergência com instituições e práticas, e carregam significações que podem ser comuns a toda uma época" (FOUCAULT, 2008, p. 134).

Ao atravessar o currículo, os discursos funcionam como “[...] práticas pelas quais os indivíduos foram levados a prestar atenção a eles próprios, a se decifrar, a se reconhecer" (FOUCAULT, 1998, p. 10). Nesse sentido, a proposta da pesquisa é investigar de que forma os sujeitos são subjetivados pelos discursos e práticas discursivas, dessa tendo como interesse “[...] uma análise dos 'jogos de verdade', dos jogos entre o verdadeiro e o falso, através dos quais o ser se constitui historicamente como experiência, isto é, como podendo e devendo ser pensado" (FOUCAULT, 1998, p. 11).

Participaram dessa pesquisa 18 docentes, os encontros aconteceram em sete datas diferentes, entre outubro de 2015 e janeiro de 2016, no próprio campo de pesquisa, nesse artigo dado o foco de análise foram selecionadas as narrativas de sete professores/as, sendo cinco mulheres e dois homens; a direção do colégio disponibilizou a biblioteca e até mesmo a sala da diretora para realização das entrevistas, tendo em vista que esses espaços ficam mais distantes das salas de aula, evitando barulho e interferências na realização da pesquisa. Antes da ida à escola nas datas estabelecidas foi necessário entrar em contato com a coordenação para saber os horários dos/as professores/as e disponibilidade para participação.

Após a transcrição de todas as entrevistas, foi feita uma tabulação para pensar normas de gênero, heteronormatividade e currículo. Assim imprimiu-se todo o material coletado; tudo que era referente às normas de gênero era identificado com o número 1 , heteronormatividade com o número 2 e currículo com o número 3. Feito esse primeiro trabalho, a partir das narrativas apresentadas e considerando discurso como categoria teórica, problematizaram-se os discursos que atravessavam essas narrativas e como eles agem como mecanismo de subjetivação no currículo escolar, com o intuito de produzir um sujeito específico. Nesse trabalho destacamos os dados encontrados sobre heteronormatividade, problematizando como os sujeitos são constituídos e convidados a corresponderem a esse regime político. 


\section{Vigilância da sexualidade e heteronormatividade no currículo}

As narrativas dos/das docentes nos informam que no currículo investigado há uma norma hegemônica de entender masculinidade e feminilidade, interiorizada tanto pelos/as docentes como pelos/as alunos/as, que também reforça a heterossexualidade como padrão. A masculinidade só é concebível aos corpos "marcados" pelo pênis e no polo oposto estará a feminilidade legitimada pela vagina. São construções interiorizadas e repetidas para que os sujeitos incorporem modos "verdadeiros" de se tornarem homem e mulher. Dessa forma, não é concebível que um homem seja afeminado e uma mulher seja masculinizada, ou que um homem expresse desejo por outro homem e a mulher por outra mulher, pois estarão borrando as fronteiras da normalidade, e logo não poderão ser compreendidos efetivamente como pertencentes ao que o sexo biológico "determina". Britzman (1996, p. 77) afirma que isso:

[...] resultará provavelmente no questionamento social da identidade do/a transgressor/a, bem como na penalizante insistência de que formas de masculinidade e feminilidade devem ser rigidamente opostas, como desvinculadas do processo social.

Entende-se que o que torna um gênero inteligível ${ }^{2} \mathrm{e}$ normalizado não é somente a identificação da genitália ou os cromossomos XX e XY, a correspondência das performances corporais e ao que foi construído socialmente e culturalmente como próprios de homem e de mulher também são acionados nessa empreitada. Assim, os corpos são vigiados e demarcados também por essas construções. Dessa forma, serão valorizados, postos como modelos e evidenciados os corpos que mais se aproximam desse padrão, por isso diversos discursos e práticas discursivas são requeridos para reforçar as normas de gênero, fabricando sujeitos como normais e outros como anormais.

Os corpos são insistentemente investidos e regulados para se tornarem inteligíveis, por isso aqueles que se desviam sofrem sanções reguladoras como discriminações e apelidos, conforme relato da professora Marta:

Porque meninos principalmente, assim, eles são muito preconceituosos quando você vê um outro menino que não quer seguir o sexo masculino deles, puxa mais pra o sexo feminino, então discrimina, eles botam apelido, eles criam... falta de respeito mesmo. (MARTA)

\footnotetext{
${ }^{2}$ Para Butler (2003, p. 38), gêneros inteligíveis “[...] são aqueles que, em certo sentido, instituem e mantêm relações de coerência e continuidades entre seu gênero, prática sexual e desejo". 
Esses apelidos não funcionam somente para dar um novo nome aqueles que se desviam da norma, mas como mecanismo de julgamento e classificação. Aqueles que estão no lugar inventado como normal e natural, exercem o poder de colocar os corpos desviantes em um lugar inferior, não legítimo, subordinado, aqueles que escapam da norma são "os outros". Não é possível afirmar uma identidade natural, mas de subjetividades que são construídas a partir de práticas reiterativas, de uma tecnologia que buscam produzir corpos homogêneos. Entre proibições e afirmações, certo e errado, incentivos e desestímulos, reforço e silêncio os sujeitos vão se constituindo, mas nesses processos de poder surgem as resistências, pois nem sempre os corpos serão obedientes e atenderão prontamente a imposição da norma. Antes, darão seus contornos e mostrarão as possibilidades de escape.

Essas configurações podem ser observadas no espaço escolar, local no qual também se aprende sobre modos de ser homem e ser mulher, e os discursos alcançam, nomeiam, constroem pessoas e as tornam alvo de investimentos, de vigilância, de correções e de processos diversos de normalização no espaço escolar. No currículo investigado, surgem situações que podem ser problematizadas para pensar em pedagogias que constituem os/as alunos/as.

Não foi assim questão de situação problemas. Foi uma maneira de defendê-lo que eu chamei uma vez um garoto para ir ao quadro e você sabe a criança tinha aqueles trejeitos né? E, de repente começaram aquele... colocaram em questão... [...] Os colegas no caso, aí eu prontamente dei um para por aí... porque é importante pra nós professores de Matemática, de História, de Geografia, de Francês é o que ele possa dar, não é o que ele está sendo apresentado. Na maneira exterior e sim na maneira interior, que seria a capacidade dele em resolver. E aí até se aquietaram. (JÉSSICA)

Em cena existe um corpo que não se conforma com as normas, um corpo de "um garoto" que não é masculinizado. "Trejeitos" aqui se refere a construções que não são correspondentes ao sexo biológico, de desvios do que comumente é aprendido como próprios de homem, que deve ser uma postura marcada por passos firmes, punhos fortes, voz grossa, que enquadram e tornam possíveis subjetivar um corpo como visivelmente masculino. Através de construções como essa, aprende-se a olhar um corpo e identificar características que lhes são próprias ou não, essas construções, por certo interiorizadas pela turma na qual o aluno está inserido, fazem com que os/as alunos/as questionem a performance dissonante do corpo do colega. 
Atitudes como essa de dar "um para por aí...", ainda que haja uma intenção de proteger o aluno que é alvo das "brincadeiras", refletem um silenciamento que dá voz à norma e a faz ser reiterada nesse espaço; pode-se perceber como, através de situações como essa, um modelo heteronormativo continua sendo evidenciado e precisa de outro para se manter como natural.

Mesmo não revelado de forma explícita, o "questionamento" dos alunos, relatado pela professora, pode se referir a brincadeiras, piadas ofensivas, apelidos, que funcionam como mecanismos de controle que buscam alcançar o corpo do menino e também reforçar a norma a ser seguida por todos os outros meninos que ali estavam, o poder disciplinar está sendo plenamente exercido nessa experiência, ele "[...] controla continuamente os mesmos que estão encarregados de controlar" (FOUCAULT, 2014b, p. 174). Quando os/as alunos/as questionam a performance do aluno que vai ao quadro, eles estão dizendo de sua performance também, pois aquele corpo alvo dos comentários naquela situação é visto como anormal e logo existe um que é normal, que deveria ser seguido e não é. Para Louro (2015a, p. 15):

O reconhecimento do "outro", daquele ou daquela que não partilha dos atributos que possuímos, é feito a partir do lugar social que ocupamos. De modo mais amplo, as sociedades realizam esses processos e, então, constroem os contornos demarcadores das fronteiras entre aqueles que representam a norma (que estão em consonância com seus padrões culturais) e aqueles que ficam fora dela, às suas margens.

O aluno que vai ao quadro passa a ser classificado como "o outro", tomando como parâmetro e referência as performances que correspondem ao que é esperado para um corpo masculino. Dessa forma, os alunos que o classificam reconhecem como legítima e verdadeira as suas performances e isso não se dá de forma natural, eles também aprenderam como se comportar de tal forma e a entender que essa é a "verdadeira" maneira de meninos se comportarem, os gestos autorizados e as várias formas de expressão.

A fala da professora Marta também é perpassada por aprendizagens, pois ela diz que "[...] de longe você vê só homem e mulher, mas quando você conversa, você vê que tem algumas pessoas que seguem outras linhas diferente da nossa”. Aqui, é possível perceber que há uma designação que não é nomeada, mas estabelecida como modelo, e o que se diferencia dele é marcado e subjetivado como "outro". Aqueles/as que se identificam como normais exercem o poder de se representar e representar o outro, isso significa que a identidade hegemônica é estabelecida nessa relação intrínseca em que 
apresenta o diferente subalternizando sua performance e/ou silenciando-o. Louro (2015b, p. 43) considera que "[...] esse é um pensamento que elege e fixa uma ideia, uma entidade ou sujeito como fundante ou como central, determinando, a partir desse lugar a posição do 'outro', o seu oposto subordinado".

A construção de se perceber como normal é passada de forma minuciosa e é interiorizada por vezes de forma imperceptível, sendo possível afirmar que "[...] a norma não é simplesmente um princípio de inteligibilidade; é um elemento a partir do qual certo exercício de poder se acha fundado e legitimado" (FOUCAULT, 2001, p. 62). A norma aqui é legitimada por um exercício de poder em que ela se estabelece como verdade, a partir de um conjunto de discursos que a legitima e é deixado de lado o aspecto construtivo. Ela se estabelece como mecanismo para capturar todos os corpos a fim de que eles correspondam aos seus pressupostos, quando os/as alunos/as identificam traços de anormalidade no corpo do aluno que vai ao quadro, está também se afirmando como ele deveria ser, está se exercendo uma tentativa de coagir o menino a seguir os padrões desejados.

Os processos de normalização se atualizam, ganham formatos diversos, fazem com que a vigilância e o controle dos corpos não se restringem à sala de aula, mas se estendam a outros espaços. A técnica do poder não deve ser vista como centralizada, pois o que garante o reforço da norma são os detalhes, é a forma como ela alcança e penetra os corpos nas pequenas situações e nos desdobramentos. Assim, “[...] técnicas sempre minuciosas, muitas vezes íntimas, que têm sua importância porque definem um certo modo de investimento político e detalhado do corpo, uma nova 'microfísica do poder", (FOUCAULT, 2014b, 136). Aqui, a norma aparece no banheiro:

Teria apenas uma situação. Que o menino foi no banheiro e os meninos não queriam ele lá porque ele tava assim, como é que eu digo assim? É muito... Isso, trejeitos femininos. Trejeitos femininos, então eles não queriam que ele frequentasse o banheiro masculino. Então aí foi todo um trabalho pra poder parar com isso, e até que a escola mudou realmente, que antes os banheiros masculinos eram aqueles mictórios $n e ́$ ? Então ela mudou realmente para colocar o banheiro com a portinha fechada pra não ter esse problema. Pra ele aceitar que o menino tinha que frequentar o banheiro masculino, já que ele na ficha, não tinha orientação para deixar frequentar o banheiro feminino. Ele é masculino vai pro banheiro masculino. Aí teve essa situação. (MARTA)

Alguns meninos que frequentam o banheiro masculino não autorizam que um aluno que tem "trejeitos" femininos frequente o mesmo espaço que eles, e solicitam que ele use o banheiro feminino. Corresponder à norma e apresentar atributos masculinos é 
uma condição de ingresso naquele espaço, então o menino com performance feminina não pode ser considerado menino, por isso não tem autorização para usar o banheiro. A performance do menino, destoante ao que se fabricou como normal ao sexo masculino, faz com que os alunos o classifiquem como do sexo oposto, ele aqui é o "outro", o que não deve ser considerado e conhecido como menino; na mesma direção é afirmado e concebido o que é um sujeito masculino e que pode frequentar aquele espaço. Mesmo que não seja possível dizer como o menino se percebia, pois ele não foi entrevistado, e, de acordo com a professora, não havia nenhuma solicitação do aluno para que ele pudesse ser tratado como do sexo feminino. O que é perceptível nessa situação é um processo de classificação e hierarquização, regida pela heteronormatividade, o que:

“[...] subjaz a ideia de um único modelo de masculinidade possível. Algo a ser conquistado pelos indivíduos masculinos, numa luta árdua por um título a ser defendido a cada momento da vida, sob a implacável vigilância de todos" (JUNQUEIRA, 2015, p. 228).

A subdivisão arquitetônica do banheiro feita pela escola foi uma estratégia para dar um lugar específico aos alunos que frequentavam aquele espaço. Assim, o aluno com "trejeitos femininos" pôde continuar utilizando o mesmo banheiro que os alunos supostamente com "trejeitos masculinos" e mais adequados à norma naquele espaço. Talvez a escola achou ser mais fácil mexer na arquitetura da escola do que na arquitetura curricular, assim, não há a necessidade de problematizar sobre construções de gênero, tornando mais viável e mais fácil reforçar a norma, construindo um espaço onde os corpos normalizados pudessem se sentir à vontade. Ainda assim, essa atitude da escola controla outras situações e diz da formação de corpos que se conformam à norma também.

Ainda que não seja possível afirmar nada a respeito do gênero ou da sexualidade do menino, pode-se problematizar como a heteronormatividade é um regime opressor para todos os sujeitos, até para aqueles/as que se afirmam como heterossexuais, pois insistentemente, sob o olhar do outro e o próprio olhar, eles têm que se mostrar perfeitamente masculinos. Quando os corpos ultrapassam as fronteiras de inteligibilidade de gênero, uma confusão entre gênero e sexualidade pode surgir, e, a partir dessa confusão, pode-se inferir que os meninos que são afeminados sejam homossexuais. Isso pode ser percebido através das narrativas abaixo:

Menino, aqui, pela manhã, tem dois que se declararam, tem outros que a gente não sabe dizer que são, mas têm todas as ferramentas. (MARCOS) 
Então, lembro sim. Na verdade. Ele sempre foi um aluno muito expansivo, muito comunicativo, sempre deixou muito visível é... Digamos a opção sexual né? Nos trejeitos, na forma que ele falava, então a gente sabia que ele tinha uma tendência a gostar de meninos. Não é? (ROBERTA)

Ter "todas as ferramentas", "trejeitos" não significa somente perceber traços femininos no corpo masculino que podem anunciar "uma tendência" a ser homossexual. É necessário pensar como a homossexualidade é constituída nesse espaço e que discursos são acionados para se entender homossexual masculino como sinônimo de "menino afeminado". Pode-se problematizar, portanto, se alguns alunos têm todas as ferramentas e trejeitos que são referências para fabricá-los como homossexuais, e quais são as ferramentas e trejeitos que constroem o currículo heterossexual?

Dessa maneira, a performance é pensada como as pessoas são reconhecidas e nomeadas a partir dos atos reiterados ou não. Dessa forma, adquirir uma identidade não é algo que acontece de forma nata e/ou de uma vez por todas, mas sim uma construção interminável e regulada constantemente que traça fronteiras da normalidade. O corpo é investido pela cultura em que estratégias são acionadas para manter uma lógica binária assim:

O efeito do gênero se produz pela estilização do corpo e deve ser entendido, consequentemente, como a forma corriqueira pela qual os gestos, movimentos e estilos corporais de vários tipos constituem a ilusão de um eu permanentemente marcado pelo gênero (BUTLER, 2003, p. 200)

Gênero passa a ser entendido como uma norma das regulações às quais os sujeitos são submetidos para que os corpos se aproximem o máximo e sejam coerentes com seus pressupostos. Para que esse projeto tenha êxito, a tecnologia de gênero acontece em vários espaços, em todo tempo, pois, desde o nascimento, os corpos são interpelados por discursos que pretendem normalizar o ser humano. A ciência, a televisão, os livros, o cinema e uma infinidade de artefatos culturais que perpassam as experiências constituem o currículo que ensinam modos adequados para formar homens e mulheres "de verdade", atravessados/as pelas construções que, muitas vezes, os/as docentes percebem em seus/suas alunos/as, de modo que, ao olhar os corpos e as performances dos/das estudantes, olham na perspectiva de discursos normalizadores. Assim, ao problematizar as narrativas, não se julga o/a docente e sim evidencia os processos de subjetividades que a prática escolar exerce e quais discursos estão presentes na escola que a caracterizam como um espaço disciplinar. 
A narração a seguir poderia ser mais uma típica cena escolar, já que se trata de uma aluna fazendo uma pergunta ao professor, porém provocou uma tensão. A cena foi narrada no momento da entrevista que aconteceu simultaneamente com um professor e uma professora, por isso traz-se a conversa:

Paulo: - Mas aí eu acho que é uma questão, que eles talvez estejam distorcendo e exacerbando a coisa. E aí pode ser que eles nem tenham essa opção sexual, mas façam. Pronto, uma aluna do $7^{\circ}$ ano acabou de me dizer agora, ela me fez uma pergunta...

Pesquisador: - Qual foi a pergunta que ela perguntou?

Paulo:- "Professor você tem vontade beijar na boca de outro homem?" Eu disse: Não minha filha.

Sandra: - Olha só a pergunta que ela fez!

Paulo: - Aí eu perguntei a ela: "E você tem vontade de beijar na boca de outra mulher?" Ela disse, "não que eu gosto é de menino, mas se fosse pra beijar eu beijaria". Tá vendo?

Ao perguntar se o professor já teria beijado na boca de outro homem, a aluna questionou a presumida, estável e supostamente clara heterossexualidade do professor, o qual, não imaginando que aquela pergunta pudesse ser feita, surpreendeu-se e devolveu a mesma pergunta, achando, por certo, que pudesse inibir o comportamento da aluna, mas ela o desestabiliza ainda mais ao responder "não que eu gosto é de menino, mas se fosse pra beijar eu beijaria”. O diálogo que também assustou a professora Sandra demonstra como a heterossexualidade é percebida como norma, que somente a suposição de já ter beijado outro homem provoca o professor. O processo de heterossexualidade acontece de forma mais explícita com os homens, tendo em vista as vigilâncias que, desde cedo, são direcionadas aos meninos e impedem que abraços, toques e também o beijo entre homens seja uma prática de regulação constante na cultura dominante, para garantir o êxito do projeto da heterossexualidade, tornando-se necessário “[...] afastar ou negar qualquer vestígio de desejo que não corresponda à norma sancionada. O medo e a aversão da homossexualidade são cultivados em associação com a heterossexualidade" (LOURO, 2009, p. 92). O suposto beijo que poderia ter acontecido tornaria frágil a sua heterossexualidade e logo o afastaria da norma, dessa forma foi necessário fortalecer o discurso da heterossexualidade, afirmando que, de fato, o beijo nunca aconteceu.

Mas, ao contrário de assumir uma posição fixa e estável, a menina prefere transitar, dizer que gosta de meninos, mas a possibilidade de beijar a menina é algo que ela pode experimentar sem culpa, sem receio a coloca entre fronteiras, o que é algo inconcebível para a noção de uma única possibilidade de expressão sexual que perpassa pela narrativa do professor, então ele também nos questiona: “Tá vendo?” Ou seja, é como MARGENS - Revista Interdisciplinar Dossiê: Corpo, Gênero e Sexualidade Versão Digital - ISSN: 1982-5374 VOL.11. N. 17. Dez 2017. (p. 92-107) 
se estivesse perguntando "isso é possível?" ou mesmo "como pode uma menina querer beijar um menino e uma menina também?" Para Louro (2015b, p. 89):

Aqueles ou aquelas que transgridem as fronteiras de gênero e sexualidade, que as atravessam ou que, de algum modo, embaralham e confundem os sinais considerados 'próprios' de cada um desses territórios são marcados como sujeitos diferentes e desviantes.

A suposição de uma prática considerada subversiva desafia a norma naquele espaço, de forma que pensar pelo viés da multiplicidade é algo que pode assustar, ao mesmo tempo provoca a pensar na necessidade de enquadramentos aos quais os sujeitos são submetidos para assumir uma posição, um lugar e nele ficar, sem a menor possibilidade de percorrer outros territórios, viver outras realidades, desejar, sentir de outra maneira, sem precisar dizer que esse será pra sempre o modo predominante de viver. A atitude da aluna possibilita pensar para além das polaridades, nos sujeitos que não se identificam nesse regime dicotômico, de que pode ser "[...] sugestivo que se problematize o estatuto da 'verdade' da dicotomia heterossexualidade/homossexualidade como a categoria explicativa da sociedade contemporânea" (LOURO, 2009, p. 93).

Quando Paulo diz que os alunos "Talvez estejam distorcendo e exacerbando a coisa. E aí pode ser que eles nem tenham essa opção sexual, mas façam”, mais uma vez há um pressuposto de que todos naquele espaço sejam heterossexuais e estejam experimentando formas de desejo diferente, como algo passageiro. Para Britzman, esse é um dos mitos que sustenta a heterossexualidade como norma, que "[...] diz respeito de que os/as adolescentes são demasiados jovens para serem identificados/as como gays ou lésbicas" (BRITZMAN, 1996, p. 80). Dessa forma, pretende-se esconder a homossexualidade do currículo e reafirmar a heterossexualidade como única modalidade de desejo possível. Através de práticas como essa é possível afirmar que "[...] ocultar a sua homossexualidade quando já se pressupõe que ela não existe pode ser a resposta mais razoável à hostilidade estatal e à hostilidade generalizada contra as homossexualidades" (BRITZMAN, 1996, p. 83). Os mecanismos de controle e enquadramento são postos em prática para que todos/as se aproximem da norma, para que um modelo de masculinidade e feminilidade seja correspondido. Nesse projeto da heteronormatividade, alguns docentes tornam-se agentes de normalização ao pôr em prática os discursos da heteronormatividade. Por vezes, isso acontece de forma explícita e é revelado pelos/as próprios/as docentes:

Porque pelo fato da sexualidade ele começava com aquele "auê, auê" com o professor, que outro não começaria daquele jeito porque já sabia 
como era enquadrado e precisei enquadrar, o primeiro nunca precisei enquadrar mas esse último, eu tive que enquadrar. (GABRIELA)

Talvez o "auê, auê", ao qual ela se refere, diga respeito à performance dos alunos que não são heterossexuais, nem meninos masculinizados, assim as atitudes deles merecem enquadramento. Ao dizer que precisou enquadrar, nota-se que alguns indivíduos se percebem como aquele/a que está devidamente enquadrado/a, e, nesse sentido, pode exercer a autoridade de corrigir o outro. Atitudes como essa, em que sujeitos produzem tais enquadramentos são "[...] um gesto ritual por meio do qual seu alvo é desqualificado ao mesmo tempo em que seu enunciador procura se mostrar como um indivíduo perfeitamente adequado às normas de gênero" (JUNQUEIRA, 2010, p. 215). Assim, aqueles/as que rompem com os pressupostos da normalidade tornam-se alvo de pedagogias para adequá-los e adequá-las naquele espaço.

Os alunos são subjetivados pelas construções pedagógicas que criam as normas, como ocorreu com o primeiro aluno que Gabriela cita na narrativa: "outro não começaria daquele jeito porque já sabia como era enquadrado", o aluno constrói saberes nesse espaço, passa a compreender como deve e como não deve se comportar, quais atitudes são bem recebidas e quais não são. Então ele passa a se controlar, a se vigiar, a não agir confrontando a norma e sim conforme comandos de um discurso regulador. Nessa tecnologia agem modos de sujeição, ou seja, a “[...] maneira pela qual o indivíduo estabelece sua relação com essa regra e se reconhece como ligado à obrigação de pô-la em prática" (FOUCAULT, 1998, p. 26). Esse aluno, por certo deverá agir como os demais alunos heterossexuais e masculinizados, uma vez que as performances que se distanciem dessas características devem ser deixadas para outro espaço, ali todos/as devem se manter próximos dessas regras.

Os enquadramentos não são um fardo carregado somente pelos meninos homossexuais com trejeitos femininos, todos sofrem por ter que corresponder o tempo inteiro ao projeto da heteronormatividade, e, para isso, são obrigados a gostar de cores que talvez não sejam sua cor preferida, a participar de rodas de conversa com grupos que os quais talvez não haja identificação, a frequentar espaços que não gostariam, a fazer afirmações que não condizem com sua identidade, a controlar os gestos, caminhar, entonação da voz, tudo para agradar e reiterar a hegemonia da heteronormatividade. Considerando processos como esse, de vigilância, controle e correção de indivíduos sobre os outros e sobre si mesmo, pode-se afirmar que a escola funciona como "[...] um dos 
principais instrumentos de normalização, uma verdadeira tecnologia de criar pessoas 'normais', leia-se, disciplinadas, controladas e compulsoriamente levadas a serem como a sociedade se quer” (MISKOLCI, 2012, p. 18, 19).

\section{Conclusão}

A partir dos dados dessa pesquisa, foi observado que a heteronormatividade atua seguindo a ideia sexo-gênero-sexualidade, os corpos que desobedecem a essa sequência provocam um embaralhamento nas concepções de gênero e sexualidade. Além disso, os indivíduos que desobedecem a esse pressuposto são produzidos como anormais. Os sujeitos que são valorizados, postos como modelo e evidenciados são aqueles que seguem essa tríade. Todos os corpos são insistentemente investidos e regulados para se tornarem inteligíveis, ou seja, corresponder a essas prescrições.

A heterossexualidade compulsória surge como parâmetro definidor dos indivíduos, assim aqueles/as que não seguem seu regime são vítimas de correção e violência. Os corpos e as sexualidades são submetidos a processos de enquadramentos e normalização, através de disciplina e controle.

O currículo age como mecanismo de subjetivação, ensinando modos esperados de comportamento, investindo, atualizando e reforçando algumas "verdades". Assim são esperados e investe-se em comportamentos masculinizados para corpos marcados por um pênis e comportamentos femininos para corpos com vagina. Os sujeitos são insistentemente investidos e regulados por essas demarcações, por isso aqueles que se desviam sofrem sanções reguladoras como discriminações e apelidos. A arquitetura e a rotina escolar são utilizadas como ferramentas para garantir o sucesso do projeto heteronormativo.

Mas o currículo também é um lugar de resistências, onde essas "verdades" são corrompidas e rejeitadas. Marcado pela previsibilidade, o currículo é também um lugar de escape e de constante (re)invenção. Entende-se que os corpos subversivos podem desencadear processos de liberdade no currículo, para mostrar outras possibilidades, para denunciar o caráter opressor da heteronormatividade e seu desejo em produzir corpos obedientes e regulados ao seu discurso. 


\section{Referências}

ANDRADE, S. S.. A entrevista narrativa ressignificada nas pesquisas educacionais pósestruturalistas. In: MEYER, D. E.; PARAÍSO, M. A. (Orgs.) Metodologias de pesquisas pós-críticas em educação. Belo Horizonte: Mazza Edições, 2012.

BRITZMAN, D.. O que é esta coisa chamada amor - identidade homossexual, educação e currículo. Trad. T. T. Silva, Educação e Realidade, v. 21 (1), jan./jun. 1996, p. 71-96.

BUTLER, J.. Problemas de gênero: feminismo e subversão da identidade. Rio de Janeiro: Civilização Brasileira, 2003.

CAETANO, M. R. V.. Gênero e sexualidade: um encontro político com as epistemologias de vida e os movimentos curriculares. 2011228 f. Tese (Doutorado em Educação). Rio de Janeiro: Universidade Federal Fluminense, 2011.

FOUCAULT, M.. História da Sexualidade II: O uso dos prazeres. Edições Graal. Rio de Janeiro, 1998.

FOUCAULT. M.. Os anormais. São Paulo: Martins Fontes, 2001.

FOUCAULT, M.. A arqueologia do saber. 7.ed. Rio de Janeiro: Forense Universitária, 2008.

FOUCAULT, M.. Vigiar e punir: Nascimento da prisão; 42 ed. Petrópolis (RJ): Vozes, $2014 b$.

HALL, S.. Identidades culturais na pós-modernidade. Rio de Janeiro: DP\&A 1997.

HALL, S.. Da diáspora: identidades e mediações culturais. Belo Horizonte: UFMG, 2003.

JUNQUEIRA, R. D.. Currículo heteronormativo e cotidiano escolar homofóbico. Espaço do Currículo, v. 2, n. 2, Set/2009-Mar./2010, p. 208-230.

JUNQUEIRA, R. D.. Temos um problema em nossa escola: um garoto afeminado demais. Pedagogia do armário e currículo em ação. Revista Educação e Políticas em Debate. V. 4, N. 2 - ago./dez. 2015, p. 221-239.

LOURO, G. L.. Heteronormatividade e homofobia. In: JUNQUEIRA, Rogério Diniz (Org.). Diversidade sexual na educação: problematizações sobre a homofobia nas escolas. Brasília: Ministério da Educação; Unesco, 2009.

LOURO, G. L.. Pedagogias da sexualidade. In: LOURO, Guacira Lopes (Org.). O corpo educado: pedagogias da sexualidade. Belo Horizonte: Autêntica, 2015a. p. 7-34.

LOURO, G. L.. Um corpo estranho - ensaios sobre sexualidade e teoria queer. 2. ed.; 2. reimp. - Belo Horizonte: Autêntica, 2015b. 
MATTELART, A.. Introdução aos estudos culturais. São Paulo: Parábola Editorial, 2004.

MISKOLCI, R.. Teoria queer: Um aprendizado pelas diferenças. Autêntica. Belo Horizonte. 2012

OLESEN, V. L.. Os feminismos e a pesquisa qualitativa neste novo milênio. In: DENZIN, Norman K. O planejamento da pesquisa qualitativa: teorias e abordagens. Porto Alegre: Artmed, 2006.

PARAÍSO, M. A.. Metodologias de pesquisas pós-críticas em educação e currículo: trajetórias, pressupostos, procedimentos e estratégias analíticas. In: MEYER, D. E.; PARAÍSO, M. A. (Org.) Metodologias de pesquisas pós-críticas em educação. Belo Horizonte: Mazza Edições, 2012.

SILVA, T. T.. Documentos de identidade: uma introdução às teorias do currículo. Belo Horizonte: Autêntica, 1999a.

VEIGA-NETO, A.. Foucault \& a Educação. Belo Horizonte: Autêntica, 2007. 